\title{
Specimen Size and Shape Effect on the Compressive Strength of Normal Strength Concrete
}

\author{
Zoltán Gyurkón ${ }^{*}$, Rita Nemes ${ }^{1}$ \\ 1 Department of Construction Materials and Technologies, Faculty of Civil Engineering, Budapest University of Technology and \\ Economics, H-1111 Budapest, Műegyetem rkp. 3, Hungary \\ * Corresponding author, e-mail: gyurko.zoltan@epito.bme.hu
}

Received: 26 November 2019, Accepted: 24 January 2020, Published online: 17 February 2020

\begin{abstract}
Present study deals with the effect of size and shape on the compressive strength of concrete. Mixes of five different strengths were designed, all between C20/25 and C50/60 strength class (normal strength concretes). Different size specimens were casted from all mixes in cube (edge length: 50 to $200 \mathrm{~mm}$ ) and in cylinder (diameter: 60 to $150 \mathrm{~mm}$ ) shapes as well. An equation was derived to estimate the compressive strength of the differently sized specimen. The parameters of the equation were optimized based on measurement data using nonlinear least-squares method with SSE (sum of squared errors) cost function. The parameter optimization was performed in different models (estimation based on the standard strength of cube or cylinder to approximate the different size specimens' cylinder or cube strength with the edge length, the surface area or the volume as dimension data). The test results showed good agreement between the laboratory measurements and the literature data (compressive strength is decreasing with the increase of the size of the specimen). The derived estimation models showed good correlation with the measurement data and with the literature estimation models, in some cases even with lower errors. The results indicated that size effect is stronger on concretes with lower strength class due to the higher level of inhomogeneity of the material. It was observed that size effect is more significant on cube specimens than on cylinder samples, which can be caused by the side ratios of the specimens and the size of the purely compressed zone. A limit value for the size of both cube and cylinder specimens was determined, above which the size effect on compressive strength can be neglected.
\end{abstract}

Keywords

size effect, shape effect, normal strength concrete, compressive strength, parameter optimization

\section{Introduction and literature review}

Based on the work of many researchers, it became a wellknown fact that there is an effect of size differences on the strength of specimens made of concrete [1-9]. For standardization purposes, the concrete compressive strength measured on a standard cylinder $(\varnothing 150 \mathrm{~mm} \times 300 \mathrm{~mm})$ or cube $(150 \mathrm{~mm} \times 150 \mathrm{~mm} \times 150 \mathrm{~mm})$ is accepted as a unique material property [10-14]. However, the compressive strength of concrete is not unique, it depends on the sizes and shapes of specimens due to their fracture characteristics (among other factors) [15]. The so-called size effect law (SEL) was first derived by Bazant [16]. After him Kim et al. [6, 7] added the size-independent strength to SEL (Eq. (1)), with which it can approximate the nominal strength of concrete members that have similar or dissimilar crack patterns [17]. This version of SEL is called modified size effect law (MSEL) and was also proposed by Bazant as well based on a different approach [18-21].
$\sigma_{N}(d)=B f_{t}^{\prime} / \sqrt{1+d / \lambda_{0} d_{a}}+\alpha f_{t}^{\prime}$,

where $\sigma_{N}(d)$ is the size-dependent nominal strength; $f_{t}^{\prime}$ the direct tensile strength; $d$ the characteristic dimension; $d_{a}$ the maximum aggregate size; and $\mathrm{B}, \lambda_{0}$, and $\alpha$ are empirical constants. Many research investigated the effect of maximum aggregate size on the fracture process zone (FPZ) and the concept of characteristic length [22]. From a practical point of view, the most important is to get the compressive strength of a concrete specimen. Kim et al. $[6,7]$ proposed Eq. (2) to obtain the compressive strength of a cylindrical shape specimen with various sizes and height-to-diameter ratios [23].

$\sigma_{N}(h, d)=0.4 f_{c}^{\prime} / \sqrt{1+(h-d) / 5}+0.8 f_{c}^{\prime}$,

where height of cylinder specimen $h$ and diameter of cylinder specimen $d$ are in $\mathrm{cm}$. In this equation, $f_{c}^{\prime}$ is the 
maximum stress, which is usually considered as the compressive strength of concrete and determined in accordance with ASTM C 39 (2001) [10]. The study suggests that this equation is usable on cyclinders with maximum $4: 1 \mathrm{~h} / \mathrm{d}$ ratio. In this study, Kim et al. [6, 7] also reached the conclusion that Eq. (2) is independent of $d_{a}$ (if $d_{a}$ is below $25 \mathrm{~mm}$ ) and therefore it can be used for any maximum aggregate size below that.

Equation (2) gives a good estimate for cylinder specimens with higher than unique $h / d$ ratio. This equation can be generalized to contain only one size-dependent variable $(d)$, which may be applicable for both cubes and cylinders. It could be written in the following form:

$\sigma_{N}(d)=B f_{c}^{\prime} / \sqrt{1+d / S}+\alpha f_{c}^{\prime}$,

where $B[-], S\left[\mathrm{~mm}\right.$ or $\mathrm{mm}^{2}$ or $\left.\mathrm{mm}^{3}\right]$, and $\alpha$ [-] are empirical values. Using this model by knowing the size and the standard compressive strength of the sample, the nominal strength of the given sized sample can be determined. There are different possibilities to choose which size measure of a sample to use:

- diameter (in case of cylinder specimen) and edge length (in case of cube specimen) $(d)$, or

- compressed surface area $(A)$, or

- volume of the specimen $(V)$.

Equation (2) is proposed as using the standard compressive strength measured on cylinders. However, in Europe, it would be more relatable to use the standard compressive strength measured on a standard size cube specimen. Therefore, in our study, we are investigating the possibilities of using all these variables in the estimation of nominal compressive strength. For cube strength estimation, a method was proposed by del Viso which was tested on high strength concrete samples [24]. The proposed law gives the standard cube compressive strength based on compression strength measured on arbitrary size cube, the size of the specimen and an empirical constant.

\section{Materials and methods}

\subsection{Concrete mixes}

To investigate the size effect on the compressive strength of concrete, a series of laboratory experiments were conducted. First, concrete mixes were designed with normal compressive strength (from C20/25 to C50/60), which are frequently applied in the industry. To cover the whole range of normal strength concretes, five different mixes were designed: C20/25; C30/37; C35/45; C45/55 and C50/60. In the later sections of this study the $\mathrm{C} 20 / 25$ concrete will be referred as Mix 1, the C30/37 as Mix 2, the C35/45 as Mix 3, the C45/55 as Mix 4, while the C50/60 as Mix 5 for easier identification. The class of the concrete was determined based on the recommendation of MSZ EN 206:2013 (Hungarian NAD) standard [11]. The applied aggregate was normal quartz aggregate with $16 \mathrm{~mm}$ of maximum aggregate size $\left(d_{\max }\right)$ and CEM I $42.5 \mathrm{~N}$ Portland cement was applied. The chemical compsition of cement was determined by using X-ray Diffraction (XRD), its specific surface area was determined by Blaine method, while its density was measured using piknometer. The results of the measurements can be seen in Table 1. The maximum aggreagete size and cement type was constant in this research.

The water to cement ratio was 0.67 in case of Mix 1, 0.5 in case of Mix 2 and 3, and 0.35 in case of Mix 4 and 5. Besides the aggregates, cement, and water, no special additives were added to the mixes. The only difference between Mix 2 and 3, as well as between Mix 4 and 5 is their aggregate size distribution; the other parameters were kept constant. The final design of the mixes and the applied quantities can be seen in Table 2 .

As an example, the particle size distribution of Mix 2 and 3 can be seen in Fig. 1.

The grading limit curves (A, B and C) of Fig. 1 show that the grain aggregate applied is suitable for making concrete. The applied treatment was the same for all samples.

\subsection{Description of the laboratory tests}

The compressive strength of concrete was measured in our research on specimens of different sizes and shapes. The shape of the sample was either cube or cylinder because these are the two standardized shapes for concrete compressive strength testing. The edge length of the cube samples was 50,100, 150 or $200 \mathrm{~mm}$, while in case of the cylinder specimens the following samples were casted (diameter $\times$ height): $60 \times 120,100 \times 200$ and $150 \times 300 \mathrm{~mm}$.

Table 1 Chemical composition and physical properties of cement

\begin{tabular}{lc}
\hline Measured property & CEM I $42.5 \mathrm{~N}$ \\
\hline Density $\left[\mathrm{g} / \mathrm{cm}^{3}\right]$ & 3.02 \\
Specific surface density $\left[\mathrm{cm}^{2} / \mathrm{g}\right]$ & 3326 \\
$\mathrm{SiO}_{2}$ & 19.33 \\
$\mathrm{CaO}$ & 63.43 \\
$\mathrm{MgO}$ & 1.45 \\
$\mathrm{Fe}_{2} \mathrm{O}_{3}$ & 3.42 \\
$\mathrm{Al}_{2} \mathrm{O}_{3}$ & 4.67 \\
$\mathrm{SO}_{3}$ & 2.6 \\
$\mathrm{Other}$ & 5.1 \\
\hline
\end{tabular}


Table 2 Concrete mix design

\begin{tabular}{|c|c|c|c|c|c|c|}
\hline & & Mix $1 \mathrm{C} 20 / 25$ & Mix 2 C30/37 & Mix 3 C $35 / 45$ & Mix 4 C45/55 & Mix 5 C50/60 \\
\hline \multirow{5}{*}{$\begin{array}{l}\text { Aggregate } \\
{\left[\mathrm{kg} / \mathrm{m}^{3}\right]}\end{array}$} & Cement $\left[\mathrm{kg} / \mathrm{m}^{3}\right]$ & 264 & 380 & 360 & 500 & 500 \\
\hline & Water $\left[\mathrm{kg} / \mathrm{m}^{3}\right]$ & 176.09 & 190 & 180 & 175 & 175 \\
\hline & $0 / 4$ & 910.44 & 984.32 & 641.70 & 594.5 & 789 \\
\hline & $4 / 8$ & 542.39 & 357.93 & 458.40 & 424.7 & 469.5 \\
\hline & $8 / 16$ & 484.28 & 447.42 & 733.40 & 679.4 & 469.5 \\
\hline \multicolumn{2}{|c|}{ Fresh concrete density $\left[\mathrm{kg} / \mathrm{m}^{3}\right]$} & 2377.2 & 2361.9 & 2375.7 & 2376.6 & 2403 \\
\hline
\end{tabular}

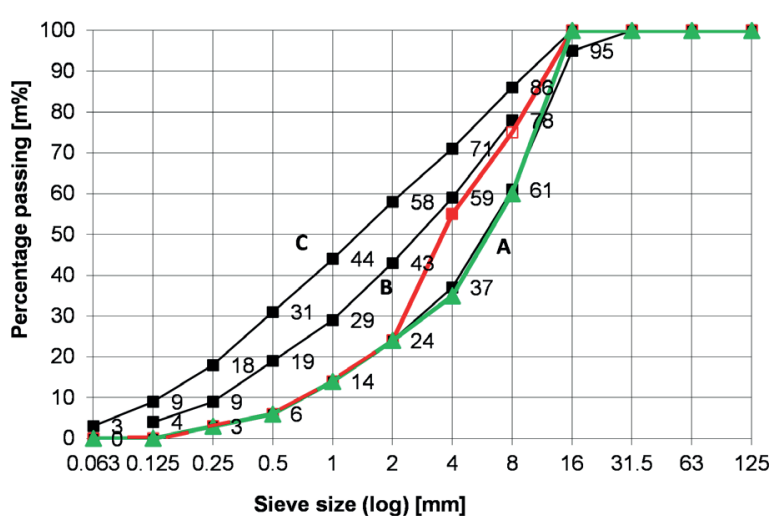

Fig. 1 Aggregate size distribution of Mix 2 (red) and Mix 3 (green)

$50 \mathrm{~mm}$ edge length was chosen as the minimum size based on the detailing rules of Eurocode (EN 1992-1-1), where the minimum size of the sample is defined as $4 \times d_{\max }$, which is in our case $64 \mathrm{~mm}$. These sample sizes were chosen because they are applied in the standards for different test methods (e.g.: $100 \mathrm{~mm}$ cube for freeze-thaw test in Eurocode). At least three specimens were produced from every size and shape, which means 105 samples in sum. The geometric data of the different samples can be seen in Fig. 2 and in Table 3, while the real samples are shown in Fig. 3.

As it was previously mentioned, the treatment of the specimens was the same. The specimens were tested for uniaxial compressive strength in the material testing laboratory of the Budapest University of Technology and Economics. The tests were conducted on an Alpha 3-3000 $\mathrm{S}$ hydraulic press (see Fig. 4) with static loading rate, which was calculated as the function of the loaded surface.

Table 3 Dimensions of the applied specimens (standard sizes are marked with bold characters)

\begin{tabular}{lc}
\hline Cube [edge length in $\mathrm{mm}$ ] & Cylinder [diameter $\times$ height in $\mathrm{mm}$ ] \\
\hline $50 \times 50 \times 50$ & - \\
- & $60 \times 120$ \\
$100 \times 100 \times 100$ & $100 \times 200$ \\
$\mathbf{1 5 0} \times \mathbf{1 5 0} \times \mathbf{1 5 0}$ & $\mathbf{1 5 0} \times \mathbf{3 0 0}$ \\
$200 \times 200 \times 200$ & - \\
\hline
\end{tabular}

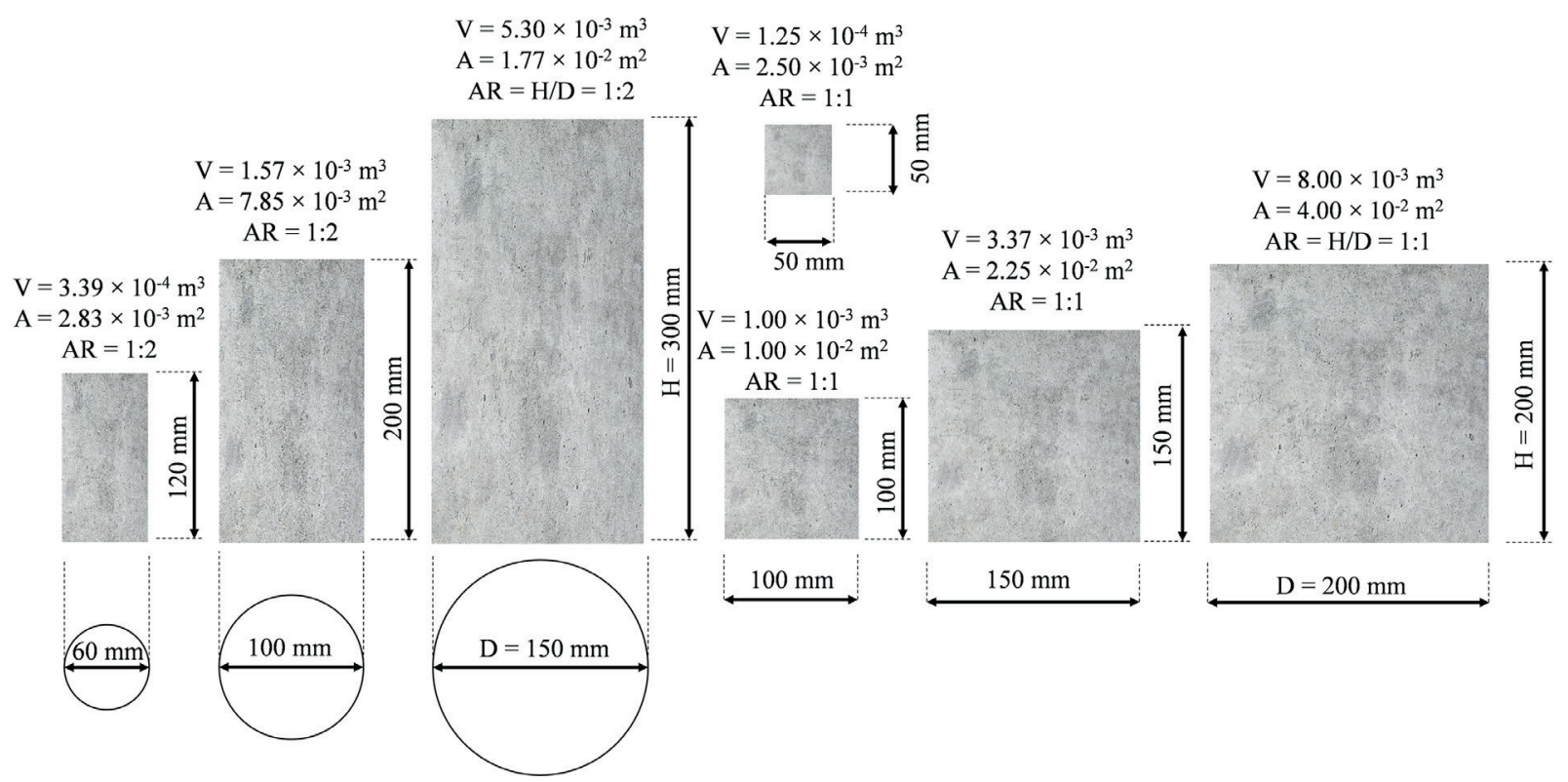

Fig. 2 The investigated samples and their geometric data ( 3 cylinders and 3 cubes); AR = aspect ratio 


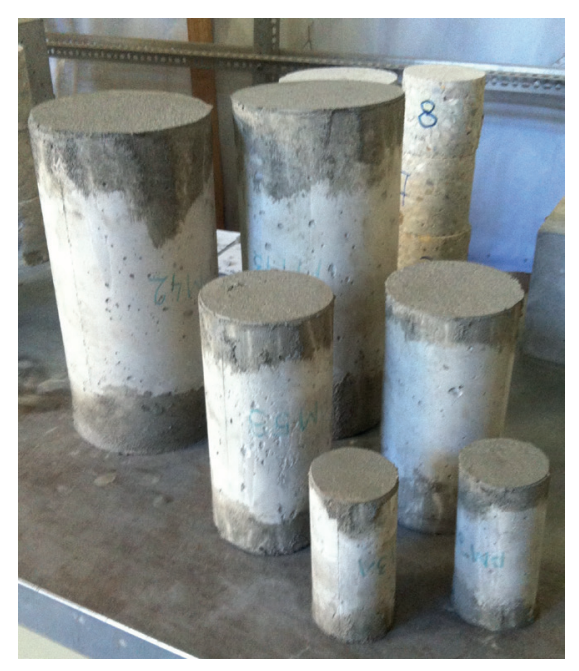

Fig. 3 Cylinder samples ready for compressive testing

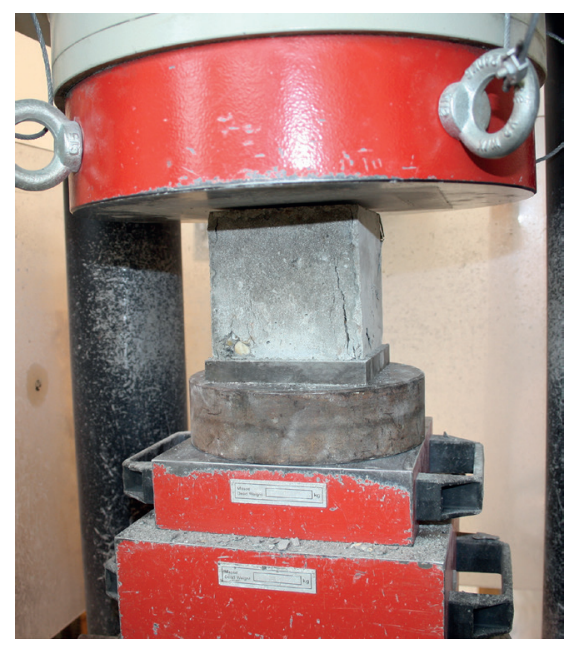

Fig. $4150 \mathrm{~mm}$ cube sample in the Alpha 3-3000 S testing machine

Besides the compressive strength, the body density of the samples was determined as well.

\subsection{Parameter optimization methodology}

There are three parameters in Eq. (3) that are aimed to be optimized, leading to a multi-parameter optimization problem. There are several approaches introduced in the literature for the solution of multi-parameter optimization problems [25-27]. The most practical applications use one of the following four methods:

- Simplex search,

- Linear or Nonlinear least squares,

- Gradient descent,

- Pattern search.

The above-mentioned methods minimize a cost function (aka. objective function), which is practically the error between the measured and simulated response. Such objective functions are the sum of absolute errors (SAE) or the sum of squared errors (SSE). The optimization is an iterative process, in which the model parameters are tuned in all steps according to the minimalized error. Thus, the simulated response tracks the measurement. Before the optimization, it is essential to define the initial state, the constraints, and the limits of the system. The number of necessary iteration steps to reach an optimal solution can be highly decreased by the appropriate choice of these values. If the values of the parameters change less than a predefined tolerance in successive iteration steps or the number of iteration steps reached its maximum, then the optimization is considered to be terminated. As a first step of this study, the different optimization methods were compared to each other on a subset of the data. The four approaches (simplex search, nonlinear least squares, gradient descent, pattern search) combined with the two mentioned objective functions (SAE, SSE) were analyzed. The

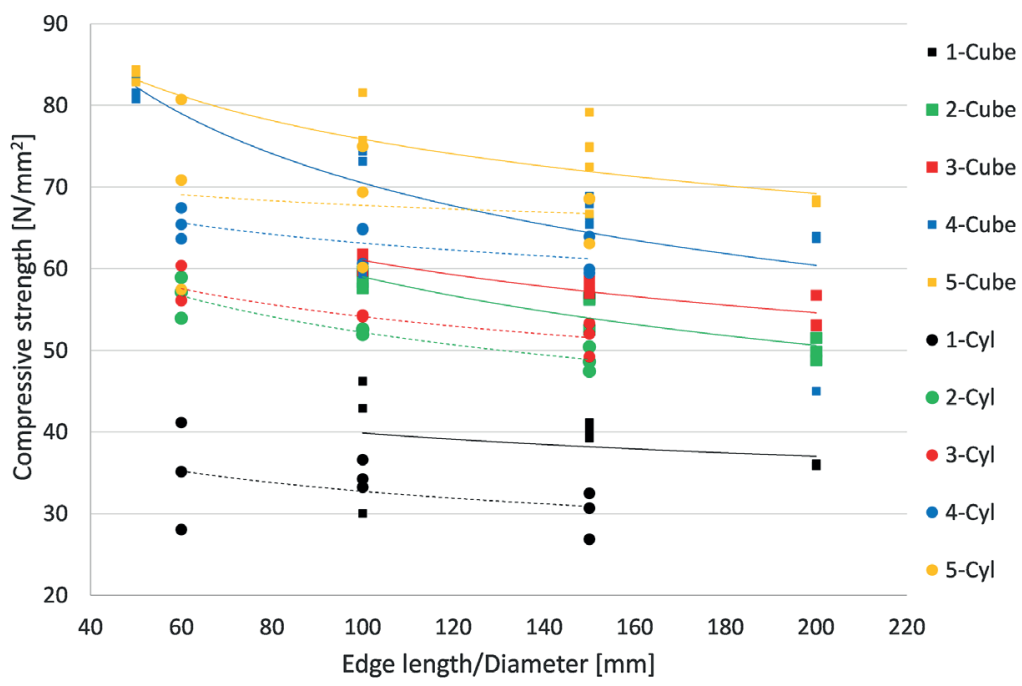

Fig. 5 Summary of compressive strength test results 
best (most precise and fast) performance was by the nonlinear adaptation (Levenberg-Marquardt) of least squares method with an SSE objective function. Similarly, accurate results were shown by the gradient descent method as well; however, the convergence was slower in that case.

\section{Results and discussion}

It is important to point out that size effect is dependent on the failure mode. The failure mode of a specimen was categorized by visual inspection on the crack pattern during the test and on the shape of the remaining material. All cube specimens had the same crack pattern, and we have found that the lateral sides got spalled during the test leading to the typical hour-glass failure mode of concrete cubes. In case of the cylinder specimens, a main inclined fracture surface was observed. The visual inspection evidences that the extent of cracking throughout the specimen is less dense in cylinder specimens that in cubes.

The results (Fig. 5) show that the compressive strength of the samples is decreasing with the increase of the size (edge length/diameter or volume), regardless of the shape or the strength class of the concrete sample. This is the expected behavior already observed by many researchers previously $[5,7,9,12,13]$. The shape and strength class influence the rate of decrease. Using the acquired data model equations were defined for every shape and mix to estimate the compressive strength based on the volume of the sample. The model equations were defined in the form of the power formula:

$$
f_{c}^{\prime}(V)=a \cdot V^{-b},
$$

where $V$ is the volume of the sample in $\mathrm{m}^{3}$, while $a$ and $b$ are constants (e.g. in case of Mix 5 for cubes, $a=55.36$; $b=0.015)$.

Table 4 Compressive strength for different volumes based on the model equation in case of Mix 5

\begin{tabular}{lcccc}
\hline $\begin{array}{l}\text { Cube edge } \\
\text { length }[\mathrm{mm}]\end{array}$ & $\begin{array}{c}\text { Cylinder } \\
\text { diameter } \\
{[\mathrm{mm}]}\end{array}$ & $\begin{array}{c}\text { Volume } \\
{\left[\mathrm{m}^{3}\right]}\end{array}$ & $\begin{array}{c}\text { Compressive strength based on } \\
\text { model equation }\left[\mathrm{N} / \mathrm{mm}^{2}\right]\end{array}$ \\
\hline 58.5 & 50.3 & 0.0002 & 82.1 & 70.0 \\
100.0 & 86.0 & 0.001 & 77.1 & 68.3 \\
126.0 & 108.4 & 0.002 & 75.0 & 67.6 \\
144.2 & 124.1 & 0.003 & 73.8 & 67.2 \\
158.7 & 136.6 & 0.004 & 73.0 & 66.9 \\
171.0 & 147.1 & 0.005 & 72.3 & 66.7 \\
181.7 & 156.3 & 0.006 & 71.8 & 66.5 \\
200.0 & 172.1 & 0.008 & 70.0 & 66.2 \\
\hline
\end{tabular}

The model equations were used for interpolation to calculate the possible compressive strengths for given volumes. The corresponding edge lengths (for cubes) and diameters (for 1:2 cylinders) with their surface were calculated as well. The range in the volume of the investigations was divided uniformly into 8 points, where the compressive strength was determined. See Table 4 as an example. Thus, the number of measurement results was increased, which could be used for the validation and verification of the proposed model, leading to a presumably more precise estimation.

Using the acquired data as measured output for the optimization scheme, the parameters of Eq. (3) could be tuned. It was aimed in our research to use Eq. (3) with different parameter sets to estimate the compressive strength of different size concrete samples. It is also aimed to find parameter sets that can be used to estimate the compressive strength of different size cube samples based on the standard compressive strength measured on a cylinder and vice versa. The notation in the following sections are the following: e.g.: Cyl-to-Cube - Cube strength estimated based on the standard strength of cylinder. In case of Cylto-Cube and Cube-to-Cyl estimations an additional step was included, during which the standard size cube compressive strength $\left(f_{c, \text { cube }}^{\prime}\right)$ was calculated from the standard size cylinder strength $\left(f_{c, c y l}^{\prime}\right)$ or vica versa $\left(f_{c}^{\prime}\right.$ of Eq. (3)). This step was required because the size effect law is valid only for one specimen shape when all the sizes are scaled up in equal proportion, This step was done based on linear regression. In the literature, there are many recommendations for that relationship. Most of them estimate the standard cube compressive strength as the 113-126\% of standard cylinder compressive strength [28]. Based on our measurements the relationship can be written in the linear form defined in Eq. (5) for normal strength concretes (with strength class between $\mathrm{C} 20 / 25$ to $\mathrm{C} 50 / 60$ ).

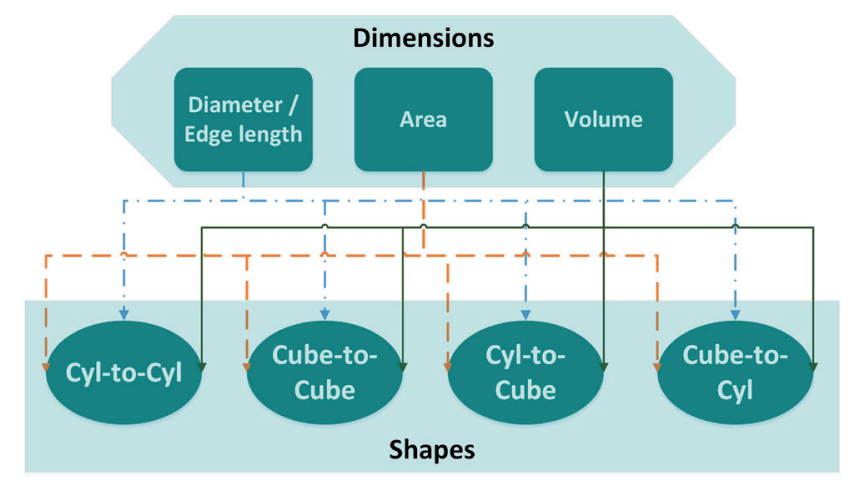

Fig. 6 Overview of the different optimization / evaluation versions 
$f_{c, \text { cube }}^{\prime}=0.907 \cdot f_{c, c y l}^{\prime}+12$

In Eq. (3) there are different possibilities to choose which size measure to use. It was also aimed to find the optimal parameters for $d$ as diameter, surface area or volume as well. In sum, it means $4 \times 3$ (Shapes $\times$ Dimensions) evaluations of the data, as it is shown in Fig. 6.

The results were compared to the most widely used approaches that can be found in the literature (original MSEL, MSEL modified by Yi et al. (cylinder and cube), del Viso) $[12,13,24]$. The initial conditions for the parameter tuning were the same (the values defined by Kim and Eo [17]) in all cases, except the value of $S$, which is strongly connected to the size measure used. The applied initial parameters can be seen in Table 5 .

\subsection{Edge length/diameter $(d)$ applied as size-related variable}

The parameters of Eq. (3) were obtained from the method described in Section 2.3 (least-squares method; SSE objective function). The optimized parameters for the different specimen shapes can be seen in Table 6 .

\subsection{Surface area $(A)$ applied as size-related variable}

From Eq. (3) using the geometry of the given specimen Eq. (6) can be derived. The parameters of Eq. (6) were obtained from the method described in Section 2.3 (leastsquares method; SSE objective function).

$\sigma_{N}(A)=B f_{c}^{\prime} / \sqrt{1+A / S}+\alpha f_{c}^{\prime}$

The optimized parameters for the different specimen shapes can be seen in Table 7.

\subsection{Volume $(V)$ applied as size-related variable}

From Eq. (3) using the geometry of the given specimen Eq. (7) can be derived. The parameters of Eq. (7) were obtained from the method described in Section 2.3 (leastsquares method; SSE objective function).

$\sigma_{N}(V)=B f_{c}^{\prime} / \sqrt{1+V / S}+\alpha f_{c}^{\prime}$

The optimized parameters for the different specimen shapes can be seen in Table 8 .

\subsection{Evaluation of the results}

The estimation results were evaluated on the basis of $\sigma_{n}(d) / f_{c}^{\prime}$ as the function of the volume. In Fig. 7, the results for estimating cylinder strength are shown from the measurements (Mix 1-5), from the literature (MSEL, Yi et al. [13])
Table 5 Initial parameter setup

\begin{tabular}{lccc}
\hline$d$ & $B$ & $\alpha$ & $S$ \\
\hline Edge length / diameter $[\mathrm{mm}]$ & & & 50 \\
Surface area $\left[\mathrm{mm}^{2}\right]$ & 0.4 & 0.8 & 500 \\
Volume $\left[\mathrm{mm}^{3}\right]$ & & & 50000 \\
\hline
\end{tabular}

Table 6 Optimized parameters based on specimen diameter/edge length

\begin{tabular}{lccc}
\hline Shape & $B$ & $\alpha$ & $S$ \\
\hline Cyl-to-Cyl & 0.55 & 0.72 & 52.32 \\
Cube-to-Cube & 0.99 & 0.41 & 76.66 \\
\hline
\end{tabular}

Table 7 Optimized parameters based on specimen surface area

\begin{tabular}{lccc}
\hline Shape & $B$ & $\alpha$ & $S$ \\
\hline Cyl-to-Cyl & 0.32 & 0.82 & 8018 \\
Cube-to-Cube & 0.55 & 0.67 & 12001 \\
\hline
\end{tabular}

Table 8 Optimized parameters based on specimen volume

\begin{tabular}{lccc}
\hline Shape & $B$ & $\alpha$ & $S$ \\
\hline Cyl-to-Cyl & 0.23 & 0.97 & 162310 \\
Cube-to-Cube & 0.36 & 0.82 & 1039100 \\
\hline
\end{tabular}

and from the own estimation models. The results show that with the increase of the specimen size, the strength ratio approaches a limit.

Based on Fig. 7 it can be seen that the functions for the same estimation model (e.g. Cyl-to-Cyl) with different size measure $(d / A / V)$ are strongly correlate to each other; in a practical point of view they can be considered as equal).

It is relatable as $A$ and $V$ are the functions of $d$ (e.g.: $A=d^{2}$ and $V=d^{3}$ for cubes). However, we would like to emphasize that in case of structures or specimens with different $h / d$ ratio this is not obviously true.

It can be seen that the estimation models from the literature and the Cyl-to-Cyl estimation models (diameter, area, and volume-based as well) quite accurately approximate the measurement results, especially in case of larger sizes. In this evaluation methodology, the Cube-to-Cyl estimation models coincide with the Cyl-to-Cyl models (same parameter set is used only $f_{c}^{\prime}$ is different).

For cubes, fewer estimation models can be found in the literature (as SEL and MSEL were defined for cylinders). Based on the results of our measurements, these estimation models of literature overestimate the strength of the specimen, especially in case of higher volumes. The Cubeto-Cube estimations show good correlation with the measurement data, regardless of the used size measure $(d / A / V)$. Similarly to cylinders, in this evaluation methodology, the Cyl-to-Cube estimation models coincide with the Cube-toCube models (same parameter set is used only $f_{c}^{\prime}$ is different). 


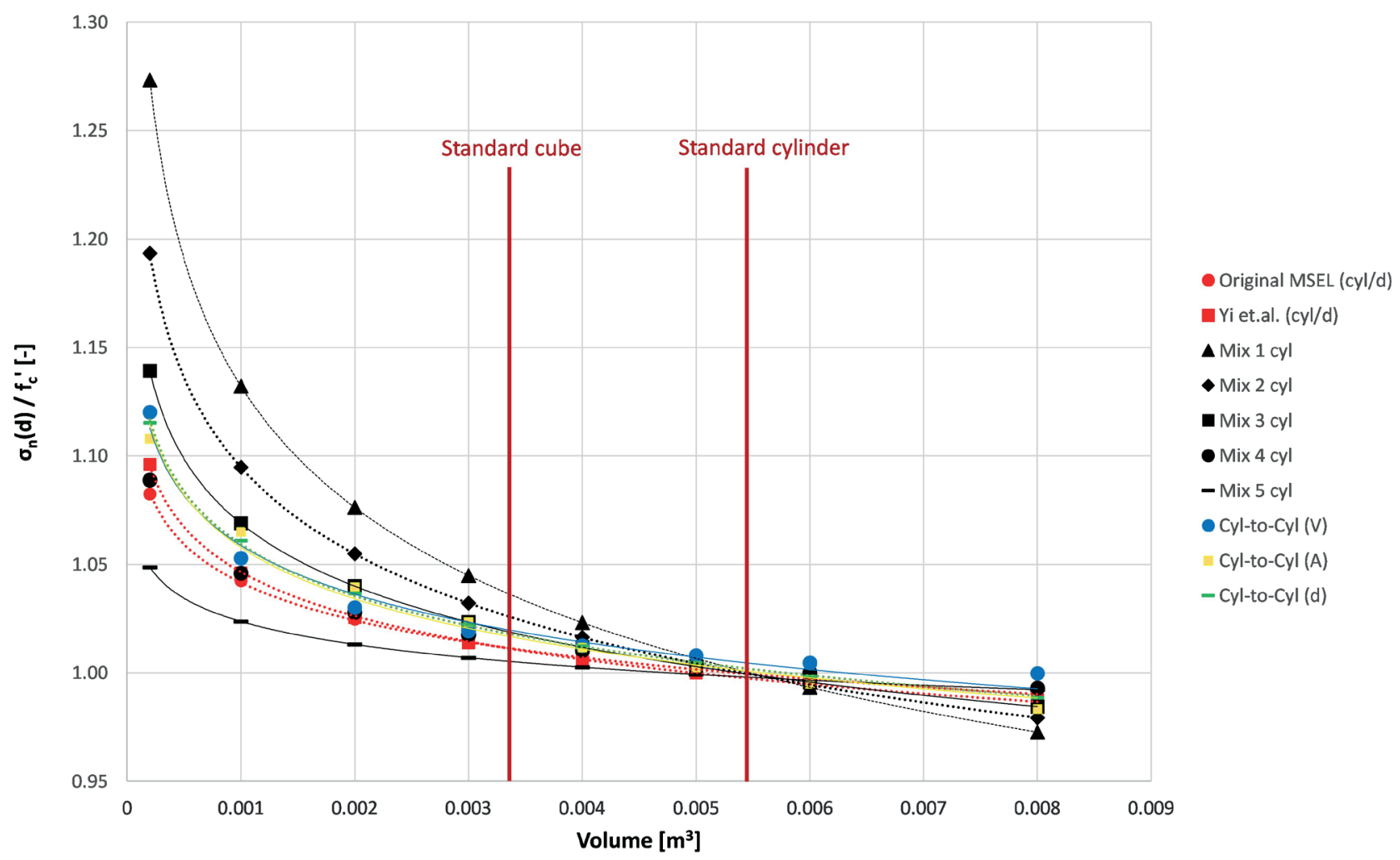

Fig. 7 Results for estimating cylinder strength (red - literature; black -measurements; other - own estimation models)

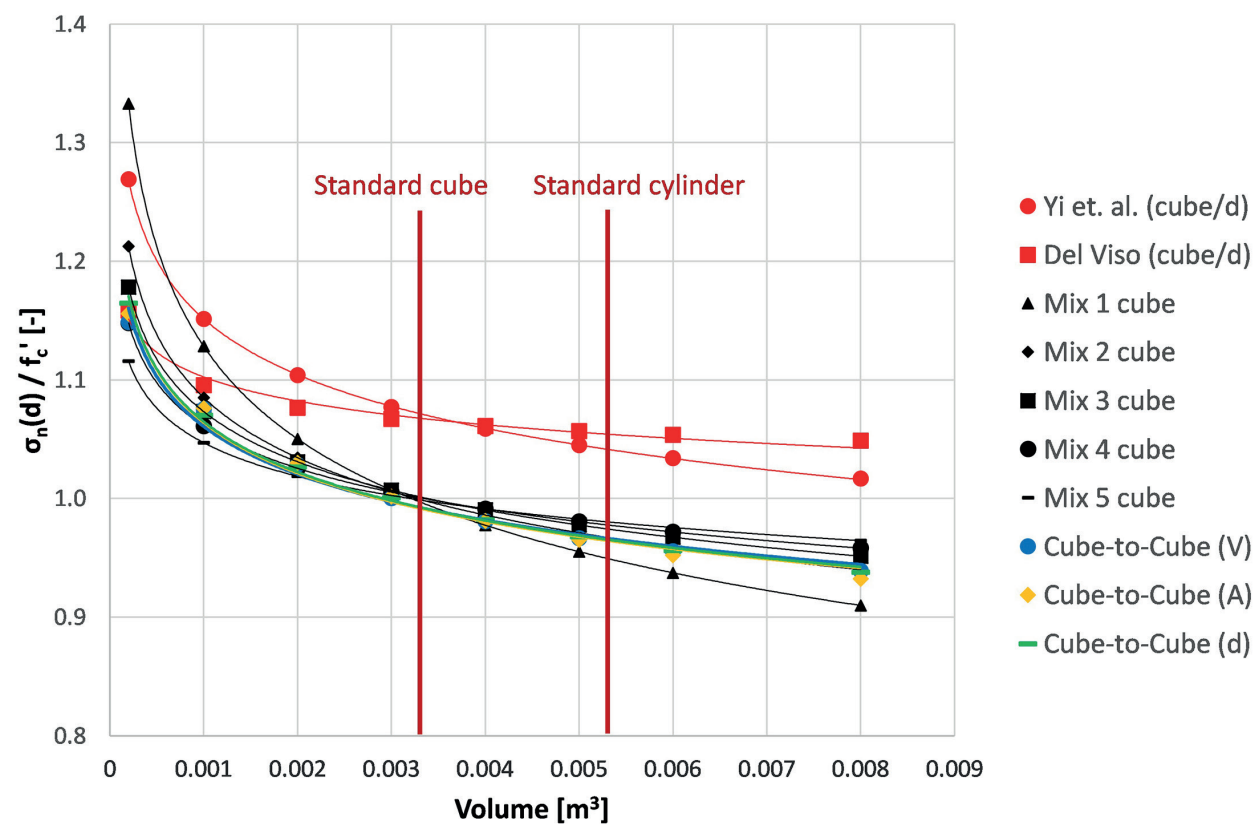

Fig. 8 Results for estimating cube strength (red - literature; black - measurements; other - own estimation models)

\subsubsection{Error analysis}

To see how accurate the different estimation models are, an error analysis was conducted. For that, the compressive strength was estimated and compared to the measurement data by using the optimized parameter sets. The error in $\mathrm{N} / \mathrm{mm}^{2}$ and in $\%$ (based on the standard cyl/cube strength) was calculated for every mix, for every size, for every estimation model. The results are summarized in Fig. 9. The average and maximum errors are also plotted. While the first shows the accuracy of a given model, the second shows its robustness (how accurate it is for very different concrete recipes). 


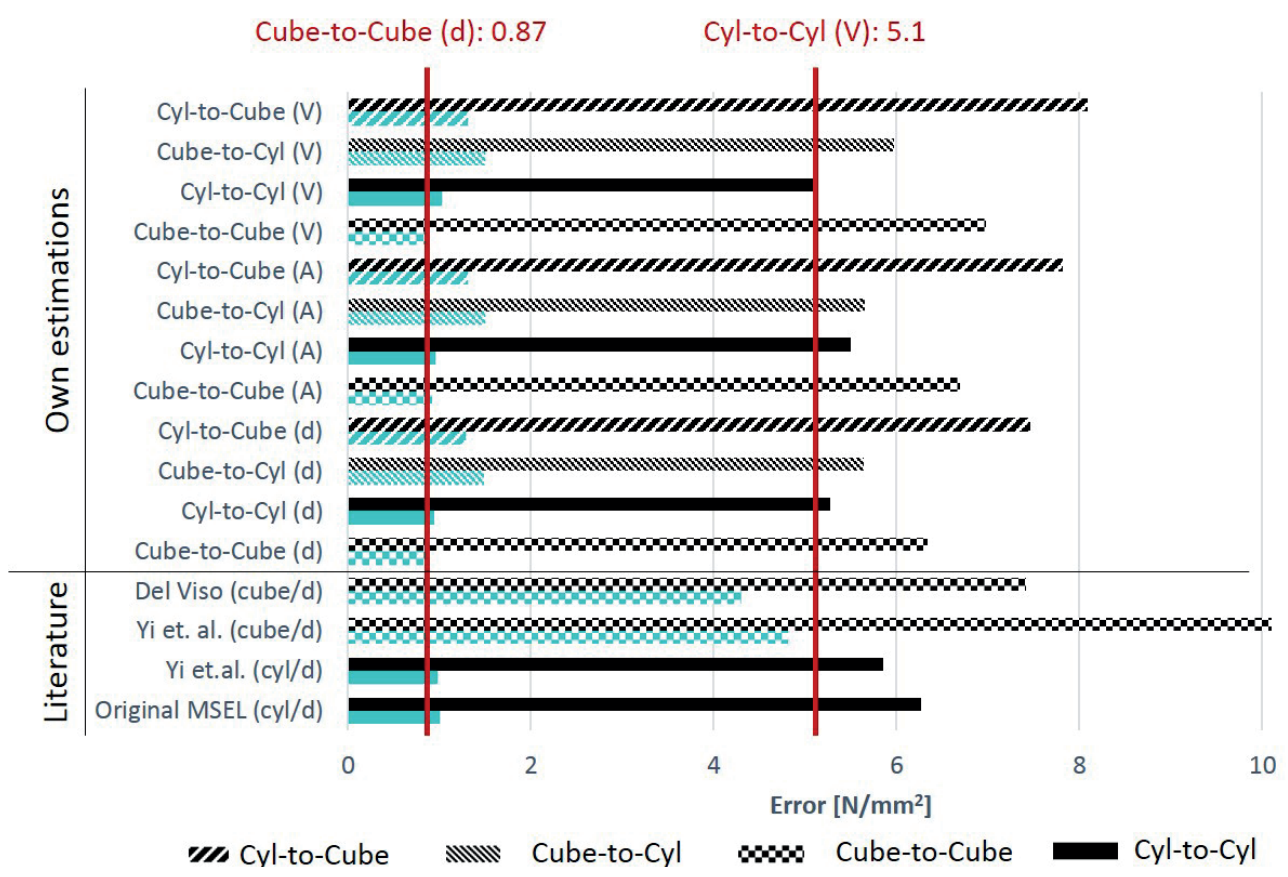

Fig. 9 Average (cyan) and maximum (black) error of the different estimation models

The lowest average error (0.87) was achieved by the Cube-to-Cube (diameter/edge length) estimation model; however, similarly low values can be found for all Cubeto-Cube and Cyl-to-Cyl models as well as for some models of the literature (MSEL, Yi et al. (cyl) [13]). The lowest maximum error belongs to the Cyl-to-Cyl (volume) model. Similar values can be found for other Cyl-to-Cyl models, for some Cube-to-Cube models and even for some Cubeto-Cyl models. Cyl-to-Cube models performed somewhat worse in this aspect. It has to be noted that the accuracy of Cyl-to-Cube and Cube-to-Cyl models are also dependent on the accuracy of Eq. (5). With a perfectly estimating Eq. (5) the same accuracy can be reached as it was reached by the Cube-to-Cube or Cyl-to-Cyl models. It is interesting to point out that in average error, there was a negligible difference between the most accurate model and the literature; however, in case of maximum error, the difference is more significant. This analysis reflects that the estimation of cube strength is always showing higher maximum error, than the estimation of cylinder strength using these models.

$$
\begin{aligned}
& e_{\max , C y l-t o-C y l} \leq e_{\max , \text { Cube-to-Cube }} \\
& e_{\max , C u b e-t o-C y l} \leq e_{\max , C y l-t o-C u b e}
\end{aligned}
$$

When the two metrics are looked together combined, the most accurate performance was done by the Cyl-to-Cyl models and Yi et al. (cyl) [13]. To estimate the cube strength from standard cube strength, the Cube-to-Cube $(d)$ model is found to be the most accurate. For the estimation of cylinder strength based on standard cube strength, the Cube-to-Cyl $(d)$ and $(A)$ models are recommended. These models have higher average error, but similar maximum error to the previous models. For the estimation of cube strength from standard cylinder strength, the Cyl-to-Cube (d) model makes the smallest error, but it has somewhat higher maximum error. However, this conversion is the least important in a practical point of view, as it is rarely used (strength classes are based on cylinder strength; it is easier to work with cubes).

In the error analysis, it was also found that with the increase of compressive strength, the average error decreases (see Fig. 10). It can be explained by the inhomogeneity of

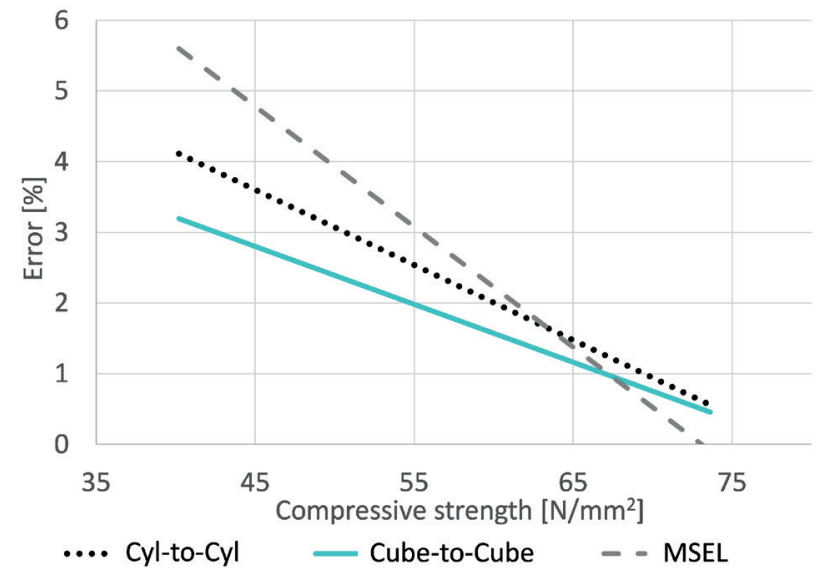

Fig. 10 Error [\%] of the estimation models in function of the standard compressive strength $\left[\mathrm{N} / \mathrm{mm}^{2}\right]$ of the mixes 
the concretes with lower compressive strength. As we are moving forward to the higher strength classes, the material becomes more and more homogeneous that explains the lower errors found.

\subsubsection{Remarks to industrial application}

As it was mentioned in Section 3.4, based on Fig. 7 and Fig. 8, with the increase of specimen size, the strength ratio decreases and approaches a certain limit. This limit corresponds to a certain size for cubes and cylinders as well. This phenomenon was analyzed by taking the difference between two strength ratio values that follow each other with $0.001 \mathrm{~m}^{3}$. As an example, one of the mixes is shown here with numerical values as well in Table 9.

The difference values are always continuously decreasing, which shows (from an engineering point of view) that the functions are approaching a limit (asymptotic). To prove that there is a limit for this function we have performed a simple limit value analysis on Eq. (3). The function was first divided by $f_{c}^{\prime}$ (same as in Figs. 7 and 8) then the size variable $(d)$ was substituted with 0 and infinite. Both resulted in two constants ( $B+\alpha$ and $\alpha$ respectively) as limit value, which shows that there is a real limit value for the function. We have decided to choose this limit value as the first volume, where the difference is smaller than a given threshold value, which, in our case, was chosen to be $0.01(1 \%)$. Thus, for all the recipes, the limit volume was derived, which is shown in Table 10. In average for cubes is about $0.006 \mathrm{~m}^{3}$ ( $\sim 182 \mathrm{~mm}$ edge length cube), above which, regardless of the increase of the size, the compressive strength of the specimen will not decrease. $182 \mathrm{~mm}$ edge length is higher than the standard size $(150 \mathrm{~mm})$ but smaller than the maximum sample size used in this study $(200 \mathrm{~mm})$. For cylinders, this value is lower, around $0.004 \mathrm{~m}^{3}$ (137 $\mathrm{mm}$ diameter 2:1 ratio cylinder). This value

Table 9 Strength ratios and the differences between them

\begin{tabular}{lcccc}
\hline $\begin{array}{l}\text { Volume } \\
{\left[\mathrm{m}^{3}\right]}\end{array}$ & \multicolumn{3}{c}{ Mix 3 $\sigma_{c}(d) / f_{c}^{\prime}[-]$} & \multicolumn{2}{c}{ Difference [-] } \\
& Cube & Cylinder & Cube & Cylinder \\
\hline 0.0002 & 1.15 & 1.14 & 0.095 & 0.070 \\
0.001 & 1.06 & 1.07 & 0.039 & 0.029 \\
0.002 & 1.02 & 1.04 & 0.022 & 0.017 \\
0.003 & 1.00 & 1.02 & 0.015 & 0.012 \\
0.004 & 0.98 & 1.01 & 0.012 & 0.009 \\
0.005 & 0.97 & 1.00 & 0.009 & 0.007 \\
0.006 & 0.96 & 1.00 & 0.007 & 0.006 \\
0.008 & 0.94 & 0.98 & - & - \\
\hline
\end{tabular}

Table 10 Strength ratio differences for every mix

\begin{tabular}{lcc}
\hline & \multicolumn{2}{c}{ Strength ratio difference [-] } \\
& Cube & Cylinder \\
\hline Mix 1 & 0.008 & 0.006 \\
Mix 2 & 0.006 & 0.005 \\
Mix 3 & 0.005 & 0.004 \\
Mix 4 & 0.006 & 0.003 \\
Mix 5 & 0.005 & 0.002 \\
Average & 0.006 & 0.004 \\
\hline
\end{tabular}

is smaller than the standard cylinder size, thus the standard size is appropriate for material testing. These values (182 $\mathrm{mm}$ for cubes and $137 \mathrm{~mm}$ for cylinders) are the minimum recommended sizes for compressive strength testing to cancel out size effect.

By looking at the curves and values in Fig. 7 and Fig. 8, it can be observed that the size effect is more significant in case of lower strength classes. The maximum and minimum values in case of Mix 1 (which has the lowest strength class: C20/25) are 1.32/1.29 and 0.90/0.99 for cubes/cylinders respectively, while in case of Mix 5 (which has the highest strength class: C50/60) these values are 1.13/1.05 and $0.95 / 0.99$. The deviation of the values in case of the higher strength class specimen is significantly lower, as it is shown in Fig. 11. This means that the size effect is dependent on the strength of the concrete specimen. As it was mentioned in Section 3.4.1, it is caused by the level of inhomogenety of the different mixes. In case of a lower strength concrete, the difference in compressive strength and Young's modulus between the cement matrix and the aggregate is significant, while in case of higher strength, the difference is decreasing. It is also worth mentioning that a lower strength concrete can be produced by many different mixes (different $v / c, h / c$, compacting, etc.), while in case of a high strength concrete, there are not that many variations.

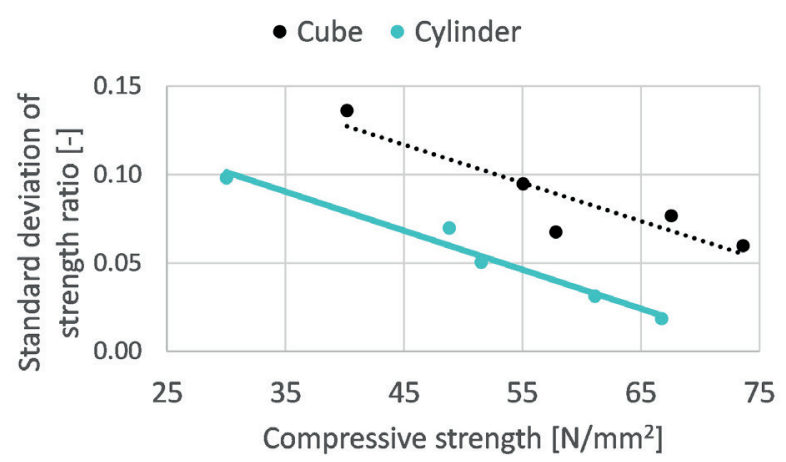

Fig. 11 Standard deviation of strength ratio of the 5 mixes in function of their standard compressive strength 
Another observation can be made based on the acquired data, which is connected to the first part of this section: size effect is more significant in case of cubes than in case of cylinders. As it was described previously, cylinders above $0.004 \mathrm{~m}^{3}$ volume can be considered to be equivalent (from a compressive strength point of view), while cubes only above $0.006 \mathrm{~m}^{3}$. The strength ratios for cubes also have higher variation than the strength ratios for cylinders. In case of a 1:2 ratio cylinder during compressive strength test, the middle 1:1 ratio zone becomes purely compressed (without tension), while in case of a cube, there is no such zone. Therefore, only a fraction of the whole volume of the cube specimen is taking part in the load-bearing, thus all small failures have higher effect on the compressive strength.

\section{Conclusions}

In the present study, the effect of size and shape (cubes with edge length from $50 \mathrm{~mm}$ to $200 \mathrm{~mm}$ and cylinders with diameter from $60 \mathrm{~mm}$ to $150 \mathrm{~mm}$ ) on the compressive strength of normal strength concrete (from C20/25 to C50/60) was investigated. Based on the size effect law of Bazant, equations with optimized parameters were derived to estimate the compressive strength of different size and shape specimens considering different dimension variables.

The main findings of the stuy are the following:

- The results showed that the laboratory measurements agree to the literature results, namely that the compressive strength is decreasing with the increase of the size of the specimen.

- In case of the smallest specimens (cubes with 50 $\mathrm{mm}$ edge length), the deviation of the compressive strength tests was higher compared to the other specimens, but in average they fit to the pattern.

- The Cyl-to-Cyl estimation model results showed good correlation with measurement data and with the literature estimation models as well.

\section{References}

[1] Bažant, Z. P. "Identification of strain-softening constitutive relation from uniaxial tests by series coupling model for localization", Cement Concrete Research, 19(6), pp. 973-977, 1989. https://doi.org/10.1016/0008-8846(89)90111-7

[2] Bažant, Z. P., Chen, E.-P. "Scaling of structural failure", Applied Mechanics Reviews, 50(10), pp. 593-627, 1997. https://doi.org/10.1115/1.3101672

[3] Bažant, Z. P., Xi, Y. "Statistical size effect in quasi-brittle structures: II. Nonlocal theory", Journal of Engineering Mechanics, 117(11), pp. 2623-2640, 1991. https://doi.org/10.1061/(ASCE)0733-9399(1991)117:11(2623)
- The Cube-to-Cube estimation model results also showed good correlation with the measurements, where the currently available literature models had higher errors, sometimes not on the safe side (strength overestimation).

- The Cube-to-Cyl estimation model showed also good correlation with the measurements, which could be useful for the industry practice.

- The Cyl-to-Cube model was also investigated and compared to the previous ones it showed higher maximum error.

- Size effect is more significant on concretes with lower strength class (e.g. C20/25) due to the higher level of inhomogeneity of the material.

- Size effect is more significant on the cube specimens (higher deviation in strength ratio), than on the cylinder samples, which can be caused by the side ratios of the specimens and the size of the purely compressed zone.

- A limit value for the size was determined for both cube $\left(0.006 \mathrm{~m}^{3}\right)$ and cylinder $\left(0.004 \mathrm{~m}^{3}\right)$ specimens, above which the size effect on compressive strength can be neglected.

In concrete research, the application of smaller size specimens has many advantages, especially for detailed material modeling where with the size of the element the computational time increasing cubically. Thus, valuable time, cost and effort could be spared, if reliable and accurate models for different size specimens would be available.

\section{Acknowledgement}

Authors are grateful to the Hungarian Scientific Research Fund (OTKA) for the financial support of the OTKA K 109233 research project.

[4] Bazant, Z. P., Xiang, Y. "Compression failure of quasibrittle materials and size effect", In: AMD-VoI185, Damage Mechanics in Composites, ASME Winter Annual Meeting, Chicago, IL, USA, 1994, pp. 143-148. [online] Available at: https://pdfs.semanticscholar.org/3b38/2cbf64fce9dc601974c9605f865b623fa832.pdf [Accessed: 03 January 2020]

[5] Bazant, Z. P., Xi, Y., Reid, S. G. "Statistical Size Effect in QuasiBrittle Structures: I. Is Weibull Theory Applicable?", Journal of Engineering Mechanics, 117(11), pp. 2609-2622, 1991. https://doi.org/10.1061/(ASCE)0733-9399(1991)117:11(2609) 
[6] Kim, J.-K., Yi, S.-T., Yang, E.-I. "Size Effect on Flexural Compressive Strength of Concrete Specimens", ACI Structural Journal, 97(2), pp. 291-296, 2000.

https://doi.org/10.14359/859

[7] Kim, J. K., Yi, S. T. "Size effect on compressive strength of concrete", In: 11th International Conference on Fracture, ICF11, Turin, Italy, 2005, pp. 5270-5275.

[8] Gyurkó, Z., Nemes, R. "Size Effect on Cylinder and Cube Strength of Concrete", Concrete Structures, 17, pp. 18-22, 2016.

[9] Balázs, G., Borján, J., Horváth, A., Schwerteczky, F. "Effect of Inhomogenity on Strength and Deformation Characteristics of Concrete", Periodica Polytechnica Civil Engineering, 37(4), pp. 313-320, 1993. [online] Available at: https://pp.bme.hu/ci/article/ view/3824 [Accessed: 03 February 2020]

[10] ASTM "C39/C39M-18 Standard Test Method for Compressive Strength of Cylindrical Concrete Specimens", ASTM International, West Conshohocken, PA, USA, 2018. https://doi.org/10.1520/C0039_C0039M-18

[11] HSI "MSZ 4798:2016/1M:2017 Concrete. Specification, performance, production, conformity, and rules of application of EN 206 in Hungary", Hungarian Standards Institution, Budapest, Hungary, 2016.

[12] Kim, J.-K., Yi, S.-T. "Application of size effect to compressive strength of concrete members", Sadhana, 27, pp. 467-484, 2002. https://doi.org/10.1007/bf02706995

[13] Yi, S.-T., Yang, E.-I., Choi, J.-C. "Effect of specimen sizes, specimen shapes, and placement directions on compressive strength of concrete", Nuclear Engineering and Design, 236(2), pp. 115-127, 2006.

https://doi.org/10.1016/j.nucengdes.2005.08.004

[14] Szalai, K. (ed.) " Quality Control of Concrete" (A beton minőségellenőrzése), Szabványkiadó, Budapest, Hungary, 1982. (in Hungarian)

[15] Dombi, J. " Strength and strength test of construction materials - 1 . Compressive strength", (Építőanyagok szilárdsága és szilárdságvizsgálata - 1. Nyomószilárdság), SZIKKTI, Budapest, Hungary, 1979. (in Hungarian)

[16] Bažant, Z. P. "Size Effect in Blunt Fracture: Concrete, Rock, Metal", Journal of Engineering Mechanics, 110(4), pp. 518-535, 1984. https://doi.org/10.1061/(ASCE)0733-9399(1984)110:4(518)

[17] Kim, J.-K., Eo, S.-H., Park, H.-K. "Size effect in concrete structures without initial crack", Fracture mechanics: Application to concrete, pp. 179-196, 1989.
[18] Bažant, Z. P. "Fracture Energy of Heterogeneous Material and Similitude", In: Shah, S. P., Swartz, S. E. (eds.) Fracture of Concrete and Rock, Springer, New York, NY, USA, 1987, pp. 390-402. https://doi.org/10.1007/978-1-4612-3578-1_23

[19] Bazant, Z. P. "Size effect in tensile and compressive quasibrittle failures I. part", In: JCI International Workshop on Size Effect in Concrete Structures, Sendai, Japan, 1993, pp. 141-160.

[20] Bazant, Z. P. "Size effect in tensile and compressive quasibrittle failures II. part", In: JCI International Workshop on Size Effect in Concrete Structures, Sendai, Japan, 1993, pp. 161-180.

[21] Bažant, Z. P., Xiang, Y. "Size Effect in Compression Fracture: Splitting Crack Band Propagation", Journal of Engineering Mechanics, 123(2), pp. 162-172, 1997. https://doi.org/10.1061/(asce)0733-9399(1997)123:2(162)

[22] Kim, J.-K. "Size effect in concrete specimens with dissimilar initial cracks", Magazine of Concrete Research, 42(153), pp. 233-238, 1990. https://doi.org/10.1680/macr.1990.42.153.233

[23] Kim, J.-K., Yi, S.-T., Park, H.-K., Eo, S.-H. "Size Effect on Compressive Strength of Plain and Spirally Reinforced Concrete Cylinders", ACI Structural Journal, 96(1), pp. 88-94, 1999. https://doi.org/10.14359/599

[24] del Viso, J. R., Carmona, J. R., Ruiz, G. "Shape and size effects on the compressive strength of high-strength concrete", Cement and Concrete Research, 38(3), pp. 386-395, 2008. https://doi.org/10.1016/j.cemconres.2007.09.020

[25] Tauzowski, P., Lógó, J., Pintér, E. "Parametric Study on the Element Size Effect for Optimal Topologies", Periodica Polytechnica Civil Engineering, 62(1), pp. 267-276, 2018. https://doi.org/10.3311/PPci.11551

[26] Pollard, D., Radchenko, P. "Nonlinear least-squares estimation", Journal of Multivariate Analysis, 97(2), pp. 548-562, 2006. https://doi.org/10.1016/j.jmva.2005.04.002

[27] Saad, L., Aissani, A., Chateauneuf, A., Raphael, W. "Reliabilitybased optimization of direct and indirect LCC of RC bridge elements under coupled fatigue-corrosion deterioration processes", Engineering Failure Analysis, 59, 570-587, 2016. https://doi.org/10.1016/j.engfailanal.2015.11.006

[28] Palotás, L. "Reinforced concrete" (A vasbeton), Magyar Építőmesterek Egyesülete, Budapest, Hungary, 1947. (in Hungarian) 